\title{
DISLOCATION DENSITY-BASED GRAIN REFINEMENT MODELING OF ORTHOGONAL CUTTING OF COMMERCIALLY PURE TITANIUM
}

\author{
Hongtao Ding and Yung C. Shin \\ Center for Laser-Based Manufacturing \\ Purdue University \\ West Lafayette, Indiana, 47907, USA
}

\begin{abstract}
Recently, machining has been exploited as a means for producing ultra-fine grained (UFG) and nanocrystalline microstructures for various metal materials, such as aluminum alloys, copper, stainless steel, titanium and nickel-based super alloys, etc. However, no predictive, analytical or numerical work has ever been presented to quantitatively predict the change of grain sizes during machining.

In this paper, a dislocation density-based viscoplastic model is adapted for modeling the grain size refinement mechanism during machining by means of a finite element based numerical framework. A novel Coupled EulerianLagrangian (CEL) finite element model embedded with the dislocation density subroutine is developed to model the severe plastic deformation and grain refinement during a steady-state cutting process. The orthogonal cutting tests of a commercially pure titanium (CP Ti) material are simulated in order to assess the validity of the numerical solution through comparison with experiments. The dislocation density-based material model is calibrated to reproduce the observed material constitutive mechanical behavior of $\mathrm{CP} \mathrm{Ti}$ under various strains, strain rates and temperatures in the cutting process. It is shown that the developed model captures the essential features of the material mechanical behavior and predicts a grain size of 100-160 nm in the chips of CP Ti at a cutting speed of $10 \mathrm{~mm} / \mathrm{s}$.
\end{abstract}

\section{Introduction}

Recently, machining has been extensively studied as a severe plastic deformation (SPD) process for the manufacture of ultra-fine grained (UFG) and nanocrystalline materials, which often possess higher strength, hardness and wearresistance than their coarse grained counterparts [1-6]. Compared to other SPD processes such as equal channel angular processing (ECAP), high pressure torsion (HPT) and cold rolling, machining only needs one pass to create large enough strain required for the creation of sub-micron grain sizes in the chip and can be performed at near-ambient temperature for high strength alloys [7]. It has been shown that machining is a flexible and controllable method for producing UFG microstructures for various metals and alloys, such as copper [1-3], aluminum alloys [3, 4], titanium [5, 6], nickelbased superalloys [6] and steels [3, 6]. To effectively design the machining process parameters for materials with varying thermo-mechanical properties and improve the quality of the resultant microstructures, it is necessary to investigate the microstructure refinement mechanism during severe deformation and is desirable to have an analytical model for predicting the grain sizes produced by machining.

There is no physics-based model, analytical or empirical, available in literature to quantitatively predict the change of grain sizes during machining to the authors' best knowledge. Large-strain in the chip formation by machining has been generally used as a qualitative measure to the grain size change in the experimental results. For example, Swaminathan et al. [3] undertook orthogonal cutting experiments of oxygen-free high thermal conductivity (OFHC) copper with cutting tools of varying rake angles and showed that the grain size in the chip reduced as the shear strain increased: average grain size was above $1 \mu \mathrm{m}$ for a shear strain of 3 , about $400 \mathrm{~nm}$ for a shear strain of 8 and about $200 \mathrm{~nm}$ for a shear strain above 13. It is noted that the aforementioned experimental conclusions, or any other experimental observations of strain-grain size relationship in those resultant UFG microstructures reported in [1-6], can not be simply extended to a different process condition or a different material, because each cutting condition for each material is unique and all the process parameters affect the resultant microstructures. Unfortunately, the effects of other important cutting process parameters, such as workpiece temperature and cutting speed, have not been clearly shown in 
measuring the resultant UFG microstructures produced by machining. Therefore, a predictive model based on the grain refinement mechanism in machining is critically needed to better design and optimize the process parameters, such as the cutting speed, temperature, depth of cut and tool geometry, etc., for producing the desirable UFG microstructures by machining.

Many theoretical attempts have been made to analyze grain refinement in a regular SPD process such as ECAP. Petryk et al. proposed a quantitative relationship between strain hardening and equiaxed grain size and modeled the grain size change for an ECAP process [8] and a multi-axis compression test [9]. Beygelzimer [10] proposed kinetic equations of grain refinement and pore generation by using a self-similarity hypothesis for the grain refining mechanism, and mathematically modeled the grain refinement during a general deformation process. These aforementioned models assumed that grain size depended only on strain, not on other involved process parameters like strain rate or temperature, and hence were not suitable for modeling a complex thermo-mechanical dynamic process such as machining.

Dislocation density-based material models are useful tools to capture grain size evolution during complex dynamic processes like machining involving multi-process variables. Recently, several dislocation density-based material models have been proposed to model the physics of grain refinement during SPD processes. Mohamed et al. [11-14] modeled the obtainable minimum grain size during a ball milling process of various metals by balancing the hardening rate arising from the dislocation generation and the recovery rate caused by dislocation annihilation. The proposed model was useful in assessing the achievable minimum grain size under different process conditions, but was not suitable for modeling the significant variance of grain sizes or microstructure textures for a monotonic deformation such as machining. Starink et al. [15] predicted grain refinement during SPD using the volume averaged number of dislocations generated and proposed a strain hardening function considering the effect of minor obstacle particles. Their proposed model dealt with grain refinement during a SPD process with a strain greater than 3 , with no strain rate dependence and a limited range of process temperature; hence, the model was not suitable for modeling grain refinement in machining with a wide range of cutting speeds and high temperature gradients. Estrin et al. [16] and Toth et al. [17] presented a set of differential equations to evaluate the dislocation density evolution rates and applied the dislocation density-based material model to grain refinement in the ECAP processes of various materials such as copper [18], aluminum [19] and IF (interstitial-free) steel [20, 21]. The nucleation of dislocations due to deformation, annihilation of dislocations due to dynamic recovery, and interaction of dislocations between the dislocation cell interiors and cell walls were evaluated based on the deformation process state variables. Their proposed dislocation density-based material model was compatible with the material constitutive models developed under varying conditions of strains, strain rates and temperatures and can be adapted to model other deformation processes with high strain rates or high temperature gradients such as a Taylor impact test [22] or a machining process. Hence their dislocation density-based material model is selected for modeling grain refinement by machining.

In this paper, the suitability of this dislocation densitybased model is investigated for predicting the microstructure evolution at large strain, high strain rate and high temperature gradients and a finite element based numerical framework is developed to model both chip formation and grain refinement in machining. A novel Coupled Eulerian-Lagrangian (CEL) finite element model embedded with the dislocation density subroutine is developed to model the severe plastic deformation and grain refinement during a steady-state cutting process. The orthogonal cutting processes of a commercially pure titanium (CP Ti) material [5] are simulated in order to assess the validity of the numerical solution through comparison with experiments. Interest in titanium and titanium alloys with UFG microstructures is motivated by their potential attractiveness for use as high-temperature structural materials. The dislocation density-based material model is calibrated to replicate the observed material constitutive mechanical behavior of $\mathrm{CP} \mathrm{Ti}$ under various strains, strain rates and temperatures in the cutting process. Modeling results are presented in chip formation, strains, strain rates, temperatures, grain sizes and dislocation densities in comparison with the actual measurements during orthogonal cutting.

\section{Dislocation density-based material model}

The dislocation density-based model is briefly presented in this section. In the model, a dislocation cell structure is assumed to form during deformation, which consists of two parts, dislocation cell walls and cell interiors, and obeys a rule of mixtures. The following describes the dislocation density evolution rates in cell interiors and cell walls, respectively:

$$
\begin{aligned}
& \dot{\rho}_{c}=\alpha^{*} \frac{1}{\sqrt{3} b} \sqrt{\rho_{w}} \dot{\gamma}_{w}^{r}-\beta^{*} \frac{6}{b d(1-f)^{1 / 3}} \dot{\gamma}_{c}^{r}-k_{o}\left(\frac{\dot{\gamma}_{c}^{r}}{\dot{\gamma}_{o}}\right)^{-1 / n} \rho_{c} \dot{\gamma}_{c}^{r} \\
& \dot{\rho}_{w}=\beta^{*} \frac{\sqrt{3}(1-f)}{f b} \sqrt{\rho_{w}} \dot{\gamma}_{c}^{r}+\beta^{*} \frac{6(1-f)^{\frac{2}{3}}}{b d f} \dot{\gamma}_{c}^{r}-k_{o}\left(\frac{\dot{\gamma}_{w}^{r}}{\dot{\gamma}_{o}}\right)^{-1 / n} \rho_{w} \dot{\gamma}_{w}^{r}(2)
\end{aligned}
$$

where the cell interior dislocation density is defined as $\rho_{c}$, and the dislocation density on the cell walls is defined as $\rho_{w}$, which is a sum of statistical dislocations and geometrically necessary dislocations. The first terms on the right side correspond to the generation of dislocations due to the activation of Frank-Read sources. The second terms denote the transfer of cell interior dislocations to cell walls where they are woven in. The last terms in each of the evolution equations represent the annihilation of dislocations leading to dynamic recovery in the course of straining. $\alpha^{*}, \beta^{*}$ and $k_{o}$ are dislocation evolution rate control parameters for the material, $n$ is a temperature sensitivity parameter, $f$ is the volume fraction of the dislocation 
cell wall, $b$ is the magnitude of the Burgers vector of the material, $d$ is the dislocation cell size, $\dot{\gamma}_{w}^{r}$ and $\dot{\gamma}_{c}^{r}$ are the resolved shear strain rates for the cell walls and interiors, respectively, and $\dot{\gamma}_{o}^{r}$ is the reference resolved shear strain rate.

It is assumed that the resolved shear strain rate across the cell walls and cell interiors are equal, $\dot{\gamma}_{w}^{r}=\dot{\gamma}_{c}^{r}=\dot{\gamma}^{r}$, which satisfies the strain compatibility along the interface between interiors and boundaries.

The resolved shear strain rate $\dot{\gamma}^{r}$ can be calculated by the von Mises strain rate $\dot{\varepsilon}$ with the Taylor factor $M$ as follows:

$$
\dot{\gamma}^{r}=M \dot{\varepsilon}
$$

Volume fraction $f$ of the dislocation cell wall, total dislocation density $\rho_{t o t}$ and grain size $d$ are given as follows:

$$
\begin{aligned}
& f=f_{\infty}+\left(f_{o}-f_{\infty}\right) e^{\left(-\frac{\gamma^{r}}{\tilde{r}^{r}}\right)} \\
& \rho_{t o t}=f \rho_{w}+(1-f) \rho_{c} \\
& d=\frac{K}{\sqrt{\rho_{t o t}}}
\end{aligned}
$$

where $f_{o}$ and $f_{\infty}$ are the initial and saturation volume fractions of cell walls, respectively, and the average cell size $d$ is assumed to scale with the inverse of the square root of total dislocation density $\rho_{\text {tot }}$. The resolved shear strain rate $\dot{\gamma}^{r}$ can then be integrated with the dislocation densities to obtain the resolved shear stress $\tau^{r}$ [18] as follows:

$$
\begin{aligned}
& \tau_{c}^{r}=\alpha G b \sqrt{\rho_{c}}\left(\frac{\dot{\gamma}_{c}^{r}}{\dot{\gamma}_{o}}\right)^{1 / m} \\
& \tau_{w}^{r}=\alpha G b \sqrt{\rho_{w}}\left(\frac{\dot{\gamma}_{w}^{r}}{\dot{\gamma}_{o}}\right)^{1 / m} \\
& \tau^{r}=f \tau_{w}^{r}+(1-f) \tau_{c}^{r}
\end{aligned}
$$

where $m$ is the strain rate sensitivity of the material.

\section{CEL modeling of steady-state cutting with grain refinement}

A novel coupled Eulerian-Lagrangian (CEL) model was developed to simulate steady-state chip formation and grain refinement in two-dimensional orthogonal cutting by using the commercial software Abaqus 6.10.1. The CEL model incorporated the dislocation density-based material model subroutines written in Fortran and calculated the dislocation fields in the workpiece during the cutting simulation. Fig. 1 shows the flow chart for CEL modeling using the dislocation density-based material model.

Fully coupled thermo-mechanical Abaqus/Explicit analysis was carried out for orthogonal cutting. Quadrilateral, four-node, linearly interpolated elements with automatic hourglass control and reduced integration were used. Fig. 2 shows the two-dimensional CEL model setup with applied mechanical boundary conditions, where cutting takes place under plane strain condition. The arbitrary-LagrangianEulerian (ALE) technique was used in the whole domain of workpiece, which was divided into four regions (Zone 1-4) to simulate material flow during cutting, as can be seen in Fig. 2. During the simulation, material flows into the workpiece mesh from the left inlet surface of zone-1, passes zone-2 around the tool tip, and exits the simulation domain from the right outlet surface of zone- 3 and the top surface of zone-4. Eulerian zones 1 and 2 remain mesh constrained at the left inlet and fully in space, respectively, while Lagrangian zones 3 and 4 grow in size generating the machined part and the chip, respectively. The chip morphology continuously evolves by either inflation or deflation until reaching a steady state. No chip separation criterion was required by the CEL model. A moderate mass scaling factor was used in the simulation to save the simulation time.

To assess the validity of the CEL model, $2 \mathrm{~d}$ orthogonal cutting conditions listed in Table 1 were simulated to compare the predicted cutting force with the experimental results [23, 24]. Workpiece material constitutive models used in the simulation are given in Table 2. A same friction coefficient of 0.4 was used to define the tool-chip interaction in the simulations as in [24]. Fig. 3 and Fig. 4 show the comparison of the cutting force and temperature predictions with the experimental results, respectively. The cutting force matches well with the experimental results for all three tool rake angles. Nearly identical chip morphology and temperature profile were predicted by the CEL model in comparison with the predictions made by Miguelez [23]. These results thus validate the CEL model for simulating $2 \mathrm{~d}$ steady-state orthogonal cutting.

Table 1. CEL model validation conditions [23, 24]

\begin{tabular}{c|cccccc}
\hline Test & Workpiece & $\begin{array}{c}\text { Tool } \\
\text { Material }\end{array}$ & $\begin{array}{c}\text { Tool } \\
\text { edge } \\
\text { Madius } \\
(\mu \mathrm{m})\end{array}$ & $\begin{array}{c}\text { Cutting } \\
\text { speed } \\
(\mathrm{m} / \mathrm{s})\end{array}$ & $\begin{array}{c}\text { Feed } \\
(\mathrm{mm})\end{array}$ & $\begin{array}{c}\text { Rake } \\
\text { angle } \\
\left({ }^{\circ}\right)\end{array}$ \\
\hline 1 & & & 20 & 2 & 0.1 & -6 \\
2 & AISI 316L & $\begin{array}{c}\text { Kennametal } \\
\text { K313 }\end{array}$ & 20 & 2 & 0.1 & 0 \\
3 & & & 20 & 2 & 0.1 & 8 \\
\hline
\end{tabular}

Table 2. Johnson-cook type constitutive model parameters for AISI 316L [24]

\begin{tabular}{c|ccccc}
\hline $\begin{array}{c}\text { Material } \\
\text { Model }\end{array}$ & $\begin{array}{c}A_{J C} \\
(\mathrm{MPa})\end{array}$ & $\begin{array}{c}B_{J C} \\
(\mathrm{MPa})\end{array}$ & $n_{J C}$ & $C_{J C}$ & $m_{J C}$ \\
\hline AISI 316L & 514 & 514 & 0.508 & 0.042 & 0.533 \\
\hline
\end{tabular}




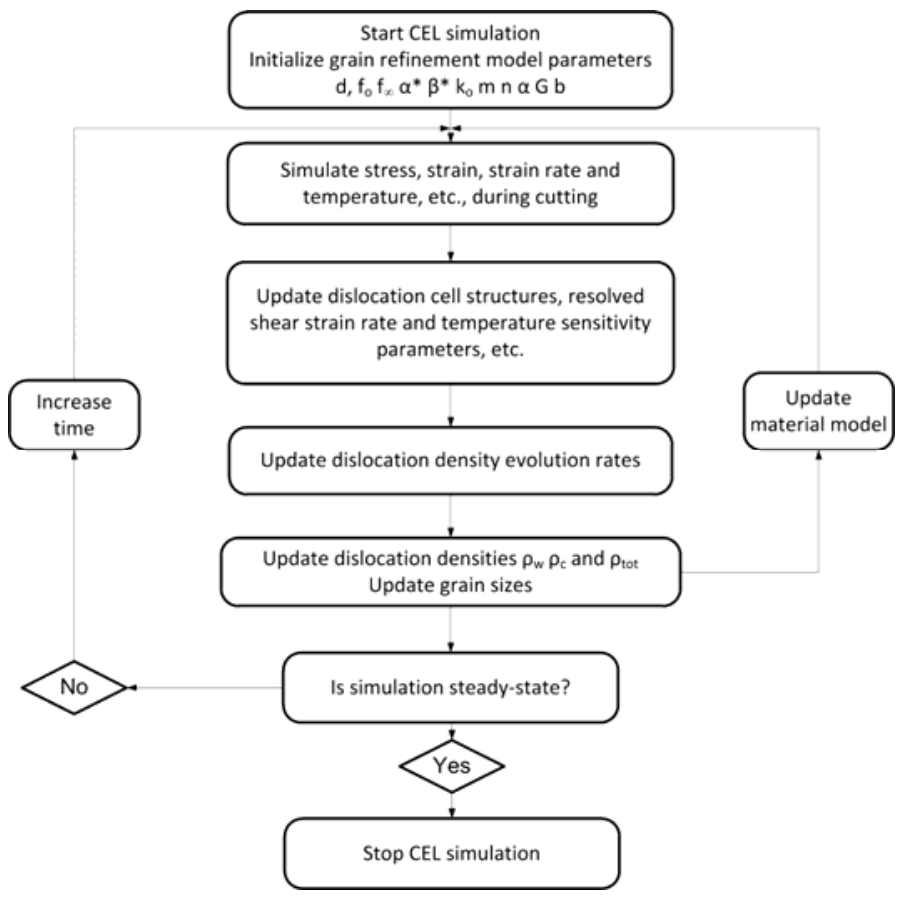

Fig. 1 Flow chart for CEL modeling using the dislocation density-based material model

$\mathrm{BC}$ regions

Zone-1, Eulerian, mesh constrained at the entrance Zone-2, Eulerian, mesh constrained Zone-3, Lagrangian, mesh constrained vertically

Zone-4, Lagrangian, mesh not constrained
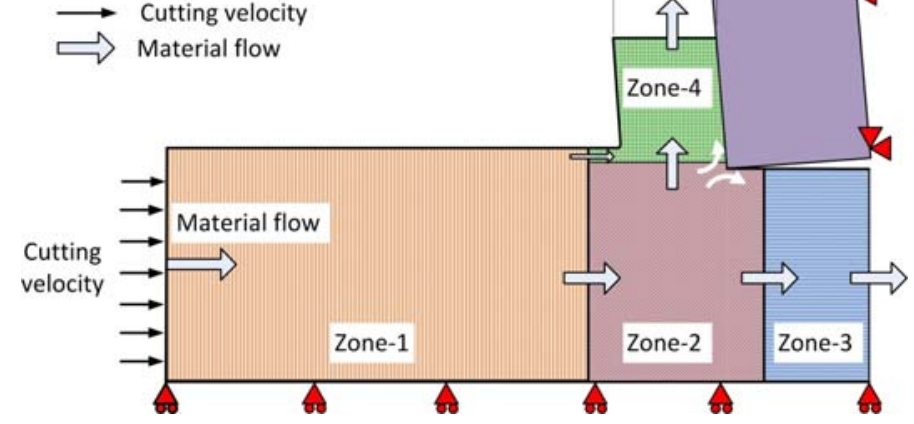

Fig. 2. CEL model setup schematic

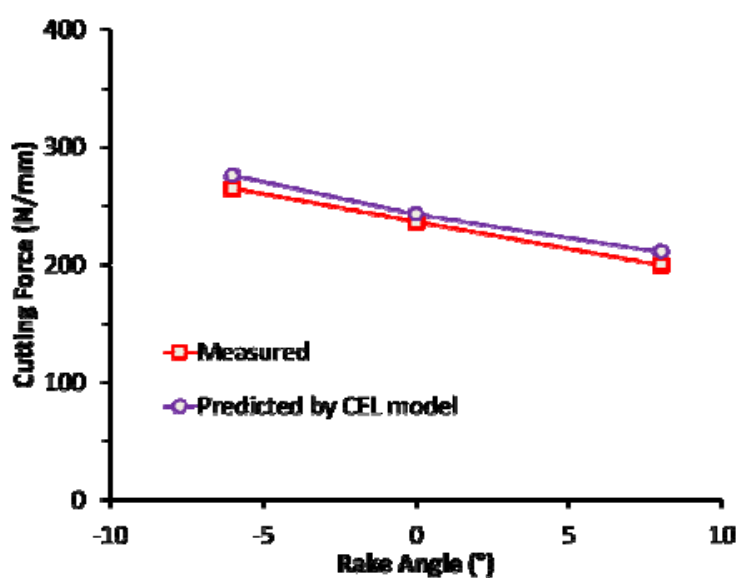

Fig. 3. Comparison of predicted cutting force with experiments
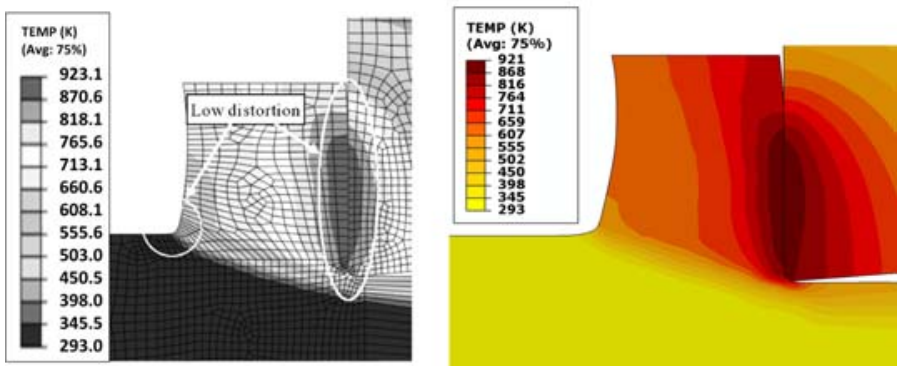

(a) Predicted by Miguelez [23] (b) Predicted by CEL model

Fig. 4. Comparison of predicted temperature distributions for Test 2

\section{Material modeling of CP Ti.}

The material properties of $\mathrm{CP}$ Ti used in the orthogonal cutting tests are given in Table 3 and 4 [25]. The material constitutive plastic model (a modified Johnson-Cook type) for $\mathrm{CP} \mathrm{Ti}$ is shown as follows:

$$
\tau=\left(B_{t i} \gamma^{n_{i t}}\right)\left(1+C_{t i} \ln \left(\frac{\dot{\gamma}}{\dot{\gamma}_{o}}\right)\right)\left(\alpha_{t i} e^{\beta_{i t}\left(\frac{T_{m}-T}{T_{m}-T_{r e f}}\right)}\right)
$$

where the model parameters are given in Table 5. Note the standardized temperature form in Eqn. (10) differs from the definition of a Johnson-Cook type plasticity model. Flow stress data for $\mathrm{CP} \mathrm{Ti}$ were obtained using the torsion tests in the temperature range from the ambient to $750{ }^{\circ} \mathrm{C}$ and at shear strain rate in the range from 0.192 to $122.0 \mathrm{~s}^{-1}$ [26], which covers the ranges of temperature and strain rate in the cutting tests [5].

Table 3. Material properties of CP Ti [25]

\begin{tabular}{c|ccccccc}
\hline Material & $\begin{array}{c}E \\
(\mathrm{GPa})\end{array}$ & $\begin{array}{c}G \\
(\mathrm{GPa})\end{array}$ & $v$ & $\begin{array}{c}b \\
(\mathrm{~nm})\end{array}$ & $\begin{array}{c}\rho \\
\left(\mathrm{kg} / \mathrm{m}^{3}\right)\end{array}$ & $\begin{array}{c}T_{m} \\
\left({ }^{\circ} \mathrm{C}\right)\end{array}$ & $\begin{array}{c}\text { Thermal expansion } \\
\left(10^{-6} /{ }^{\circ} \mathrm{C}\right)\end{array}$ \\
\hline $\mathrm{CP} \mathrm{Ti}$ & 116 & 44 & 0.32 & 0.295 & 4507 & 1668 & 8.41 \\
\hline
\end{tabular}


Table 4. Thermal parameters for CP Ti [25]

\begin{tabular}{c|cc||c|cc}
\hline $\begin{array}{c}\text { Temperatur } \\
\mathrm{e}\left({ }^{\circ} \mathrm{C}\right)\end{array}$ & $\begin{array}{c}C_{p} \\
(\mathrm{~J} / \mathrm{kg} \cdot \mathrm{K}\end{array}$ & $\begin{array}{c}k \\
(\mathrm{~W} / \mathrm{m} \cdot \mathrm{K})\end{array}$ & $\begin{array}{c}\text { Temperatur } \\
\mathrm{e}\left({ }^{\circ} \mathrm{C}\right)\end{array}$ & $\begin{array}{c}C_{p} \\
(\mathrm{~J} / \mathrm{kg} \cdot \mathrm{K}\end{array}$ & $\begin{array}{c}k \\
(\mathrm{~W} / \mathrm{m} \cdot \mathrm{K})\end{array}$ \\
\hline 25 & 522.3 & 15.5 & 476.85 & 621.9 & 13.8 \\
26.85 & 537.8 & 15.5 & 526.85 & 622.4 & 13.6 \\
76.85 & 567.8 & 15.3 & 576.85 & 622.4 & 13.4 \\
126.85 & 586.6 & 15.1 & 626.85 & 622.3 & 13.2 \\
176.85 & 598.9 & 14.9 & 676.85 & 621.7 & 13.0 \\
226.85 & 607.2 & 14.7 & 726.85 & 621 & 12.8 \\
276.85 & 612.8 & 14.5 & 776.85 & 620.2 & 12.6 \\
326.85 & 616.7 & 14.3 & 826.85 & 619.2 & 12.4 \\
376.85 & 619.3 & 14.1 & 876.85 & 618.1 & 12.2 \\
426.85 & 620.9 & 13.9 & & & \\
\hline
\end{tabular}

Table 5. Constitutive model parameters for CP Ti [26]

\begin{tabular}{c|cccccccc}
\hline Material & $\begin{array}{c}B_{t i} \\
(\mathrm{MPa})\end{array}$ & $n_{t i}$ & $C_{t i}$ & $\alpha_{t i}$ & $B_{t i}$ & $\begin{array}{c}T_{\text {ref }} \\
\left({ }^{\circ} \mathrm{C}\right)\end{array}$ & $\begin{array}{c}T_{m} \\
\left({ }^{\circ} \mathrm{C}\right)\end{array}$ & $\begin{array}{c}\dot{\gamma}_{o} \\
\left(\mathrm{~s}^{-1}\right)\end{array}$ \\
\hline $\mathrm{CP} \mathrm{Ti}$ & 294.15 & 0.294 & 0.053 & 0.021 & 3.862 & 150 & 1668 & 0.192 \\
\hline
\end{tabular}

To calibrate the dislocation density model parameters, which are unknown in literature for this material, the dislocation density-based material model was programmed with Matlab to simulate the stress-strain curves at different temperatures and strain rates. The goal of the calibration was to duplicate the stress-strain relationships with the dislocation density model under the same conditions used in the torsion tests of CP Ti. The dislocation density evolution rate control parameters, i.e., the dynamic coefficients of dislocation generation $\left(\alpha^{*}\right)$, interaction between the cell walls and interiors $\left(\beta^{*}\right)$ and dislocation annihilation $\left(k_{o}\right)$, have been calibrated according to the measured flow stress data. The dislocation density-based plasticity predicts the stress-strain relationships at different temperatures and strain rates and the simulation results are compared with the experimental data as well as calculations using the constitutive model in Eqn. (10) as can be seen in Fig. 5. The calibrated dislocation density model parameters are given in Table 6 . The identified model parameters have been proved accurate enough to predict the stress-strain relationships under different temperatures and strain rates in comparison with experimental data, which validates the dislocation density-based material model for $\mathrm{CP}$ Ti.

The reference strain rate was set as $100 \mathrm{~s}^{-1}$ because the cutting speed used in the experiments was as low as $0.01 \mathrm{~m} / \mathrm{s}$ and the resultant strain rate in the primary shear zone was close to $100 \mathrm{~s}^{-1}$. Constant parameters $\alpha^{*}$ and $\beta^{*}$ were identified as 0.03 and 0.058 , respectively, which were close to the values used for the models of $\mathrm{Cu}[16-18]$ and IF steel [20, 21]. The temperature sensitivity coefficients $m$ and $n$, dislocation annihilation rate parameter $k_{o}$ were determined to be temperature-dependent as follows:

$$
\begin{aligned}
& m=A / T \\
& n=B / T \\
& k_{o}=1.17 \times 10^{-5}(T+273.15)^{2.05}
\end{aligned}
$$

Eqns. 11 and 12 were adapted from [22] and $A$ and $B$ were identified to be 60,000 and 29,000 , respectively. Since the cutting temperature in the experiments were about $100{ }^{\circ} \mathrm{C}$, the resultant $m$ and $n$ were calculated to be about 150 and 50 , respectively, which are close to the values that have been used for $\mathrm{Cu}, \mathrm{Al}$ and IF steel [16-21]. Eqn. 13 indicates an increase of annihilation rate of $k_{o}$ as the workpiece temperature $T\left({ }^{\circ} \mathrm{C}\right)$ increases. A constant $k_{o}$ was usually used in ECAP models because the temperature profile is more uniform during the ECAP process than in machining. For the temperature range from ambient to $750{ }^{\circ} \mathrm{C}, k_{o}$ ranges from 2.9 to 17.8 for $\mathrm{CP}$ Ti. The model was also used to study the parameter sensitivity, and it was found that the model prediction was insensitive to the Initial dislocation densities. The other non-mentioned material constants were generally derived from the models for copper, aluminum and steel [16-22].

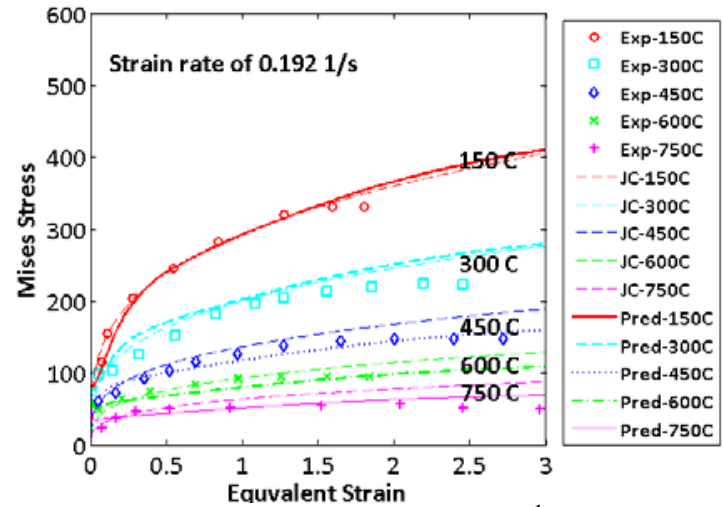

(a) Strain rate of $0.192 \mathrm{~s}^{-1}$

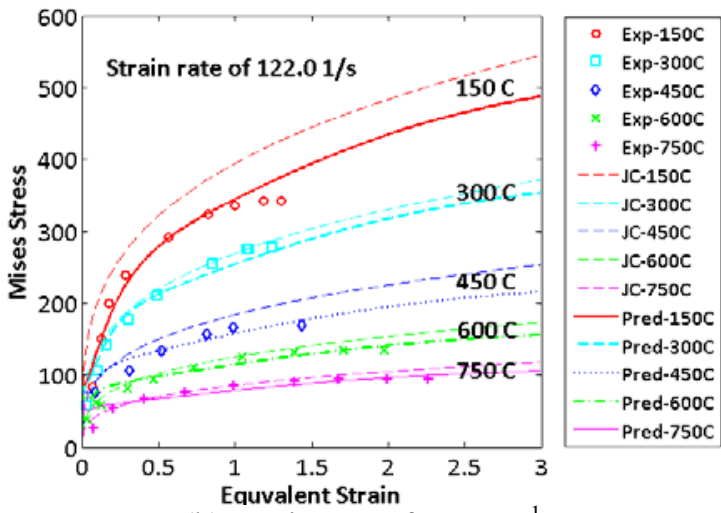

(b) Strain rate of $122.0 \mathrm{~s}^{-1}$

Fig. 5. Dislocation density-based plasticity model predictions for CP Ti. 
Table 6. Dislocation density-based material model parameters for CP Ti

\begin{tabular}{|c|c|c|c|c|c|c|c|c|c|c|c|c|c|c|c|c|c|}
\hline \multirow{2}{*}{ Material } & \multicolumn{3}{|c|}{ Dislocation rate control } & \multicolumn{4}{|c|}{$\begin{array}{c}\text { Temperature sensitivity } \\
\text { control }\end{array}$} & \multicolumn{6}{|c|}{ Process constants } & \multicolumn{4}{|c|}{ Physical constants } \\
\hline & $\alpha^{*}$ & $\beta^{*}$ & $k_{o}$ & $\begin{array}{c}A \\
(\mathrm{~K})\end{array}$ & $\begin{array}{c}B \\
(\mathrm{~K})\end{array}$ & $m$ & $n$ & $\dot{\gamma}_{o}$ & $f_{o}$ & $f_{\infty}$ & K & $M$ & $\tilde{\gamma}^{r}$ & $\begin{array}{c}\rho_{w o} \\
\left(\mathrm{~mm}^{-2}\right)\end{array}$ & $\begin{array}{c}\rho_{c o} \\
\left(\mathrm{~mm}^{-2}\right)\end{array}$ & $\begin{array}{c}b \\
(\mathrm{~nm})\end{array}$ & $\alpha$ \\
\hline $\mathrm{CP} T \mathrm{i}$ & $\begin{array}{c}0.0 \\
3 \\
\end{array}$ & 0.0058 & $\begin{array}{l}2.9- \\
17.8 \\
\end{array}$ & $6 \mathrm{E} 4$ & 2.09E4 & $\begin{array}{l}60- \\
150 \\
\end{array}$ & $\begin{array}{r}20- \\
50 \\
\end{array}$ & 100 & 0.25 & 0.07 & 10 & 3.06 & 3.2 & $1.21 \mathrm{E5}$ & $1.3 \mathrm{E} 4$ & 0.295 & 0.25 \\
\hline
\end{tabular}

\section{Simulations of grain refinement by machining}

To assess the validity of the numerical solution of dislocation density material model, the grain refinement orthogonal cutting experiments to be simulated for $\mathrm{CP} \mathrm{Ti}$ are given in Table 7. Two tool rake angles were varied to study the effect of strains and a slow cutting speed of $0.01 \mathrm{~m} / \mathrm{s}$ was used to ensure low cutting temperature in the deformation zone and to suppress grain dynamic recovery.

Table 7. Grain refinement experiments to be simulated for $\mathrm{CP}$

\begin{tabular}{c|ccccc}
\multicolumn{6}{|c}{ Ti [5] } \\
\hline Material & Test & $\begin{array}{c}\text { Initial } \\
\text { grain size } \\
(\mu \mathrm{m})\end{array}$ & $\begin{array}{c}\text { Cutting } \\
\text { speed } \\
(\mathrm{m} / \mathrm{s})\end{array}$ & $\begin{array}{c}\text { Feed } \\
(\mathrm{mm})\end{array}$ & $\begin{array}{c}\text { Rake } \\
\text { angle } \\
\left({ }^{\circ}\right)\end{array}$ \\
\hline \multirow{2}{*}{$\mathrm{CP} \mathrm{Ti}$} & Ti-1 & 60 & 0.01 & 0.3 & 20 \\
& Ti-2 & 60 & 0.01 & 0.3 & -20 \\
\hline
\end{tabular}

\subsection{Simulation results of deformation field}

Fig. 6 shows the strain rate predictions by the CEL model for orthogonal cutting of CP Ti with a rake angle of $20^{\circ}$ in comparison with the strain rate measurement using a high speed camera by Shankar et al. [5]. The strain rate prediction matched well with the measurement such that its magnitude was at the same level as the measurement and their contours were very similar. The measured high shear strain rate zone was slightly wider than the prediction. The predicted chip morphology was nearly identical to the actual chip, as can be seen in Fig. 6. Effective strains were also tracked along the middle line of the chip and about $32 \mu \mathrm{m}$ beneath the machined surface. Fig. 7 shows the comparison of the predicted effective strains for cutting of $\mathrm{CP} \mathrm{Ti}$ with a rake angle of $20^{\circ}$ and the actual measurements, which again are in good agreement. The average effective strain in the chip was predicted to be about 1.5 and 3.8 for the rake angle of $20^{\circ}$ and $-20^{\circ}$, respectively, while the measured strains were 1.4 and 3.5 for the rake angle of $20^{\circ}$ and $-20^{\circ}$, respectively. Largest strains were predicted in the secondary shear zone along the tool-chip contact and on the machined surface. A very steep strain gradient was predicted in a shallow layer below the machined subsurface. Fig. 8 shows the predictions of workpiece temperature during cutting with the two different rake angles. The predicted cutting temperature in the shear zone was increased from ambient to 70 ${ }^{\circ} \mathrm{C}$ and $150^{\circ} \mathrm{C}$ for the rake angle of $20^{\circ}$ and $-20^{\circ}$, respectively.

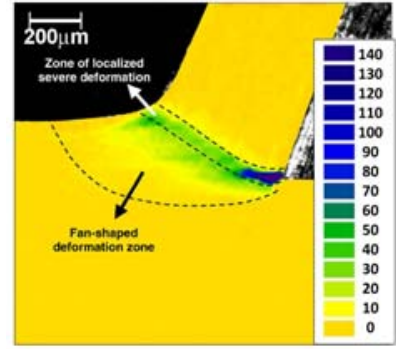

(a) Measured [5]

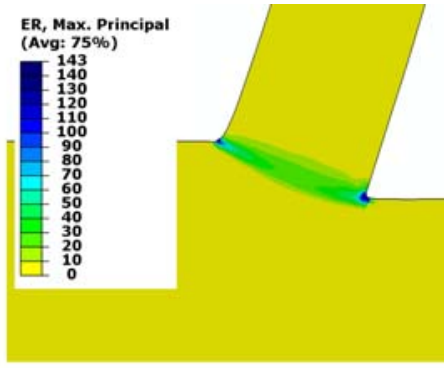

(b) predicted
Fig. 6 Strain rate predictions by the CEL model for orthogonal cutting of $\mathrm{CP} \mathrm{Ti}$ with a rake angle of $20^{\circ}$

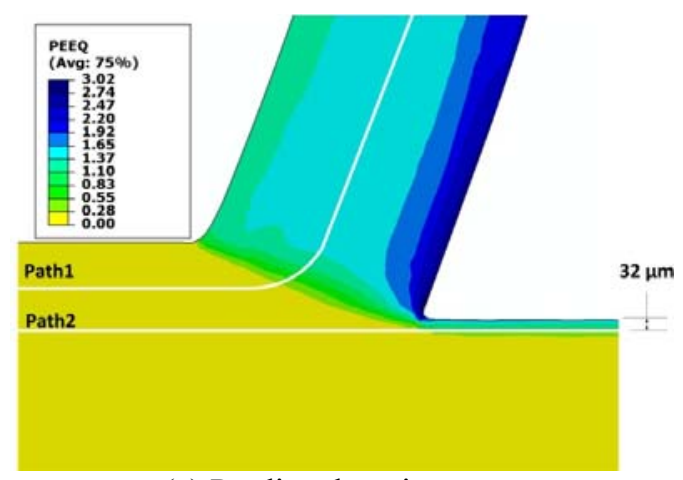

(a) Predicted strains

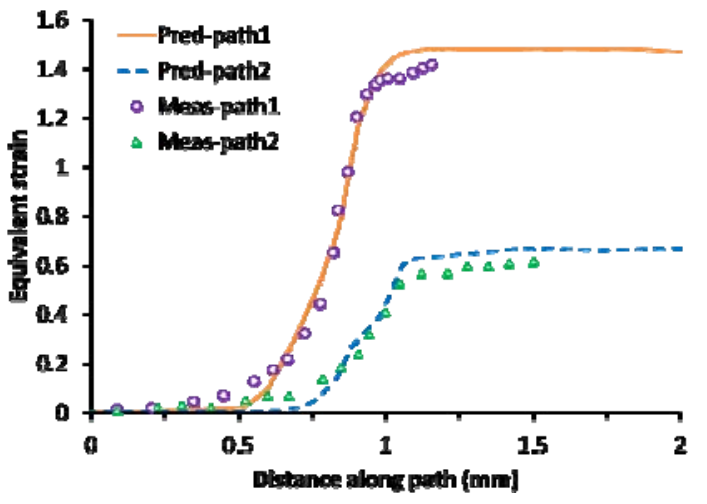

(b) Measured strains along the paths

Fig. 7 Effective strain predictions by the CEL model for orthogonal cutting of $\mathrm{CP} \mathrm{Ti}$ with a rake angle of $20^{\circ}$ 
Table 8. Grain refinement predictions

\begin{tabular}{c|ccccc}
\hline Test & Rake angle $\left(^{\circ}\right)$ & $\begin{array}{c}\text { Measured grain size } \\
\text { in chip }(\mathrm{nm})\end{array}$ & $\begin{array}{c}\text { Measured grain size } \\
\text { near the machined } \\
\text { surface }(\mathrm{nm})\end{array}$ & $\begin{array}{c}\text { Predicted grain size } \\
\text { in chip }(\mathrm{nm})\end{array}$ & $\begin{array}{c}\text { Predicted grain size } \\
\text { near the machined surface } \\
(\mathrm{nm})\end{array}$ \\
\hline Ti-1 & 20 & Min. of 100 & $\approx 100$ & $\begin{array}{c}\text { Min. of } 110 \\
\text { Avg. 146.3 } \pm 13.6\end{array}$ & $\approx 99$ \\
\hline Ti-2 & -20 & Min. of 100 & $\approx 100$ & $\begin{array}{c}\text { Min. of } 93 \\
\text { Avg. 128.7 }\end{array}$ & $\approx 103$ \\
\hline
\end{tabular}

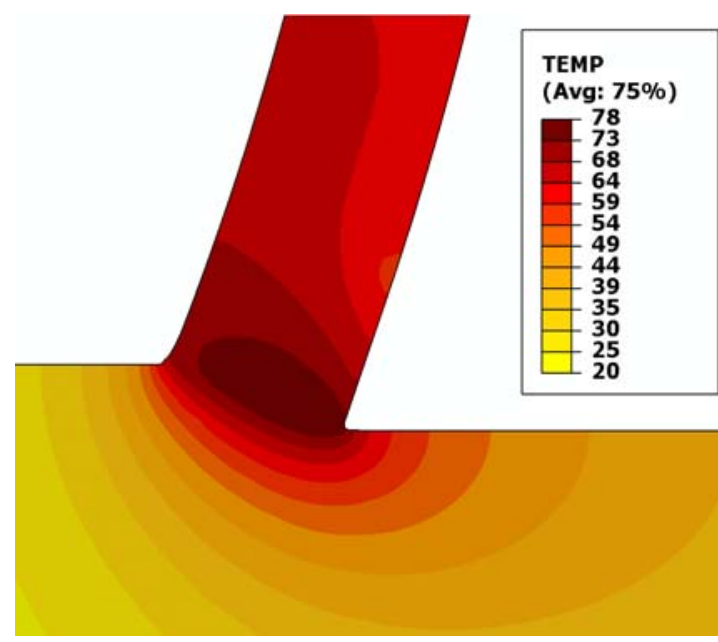

(a) Rake angle $20^{\circ}$

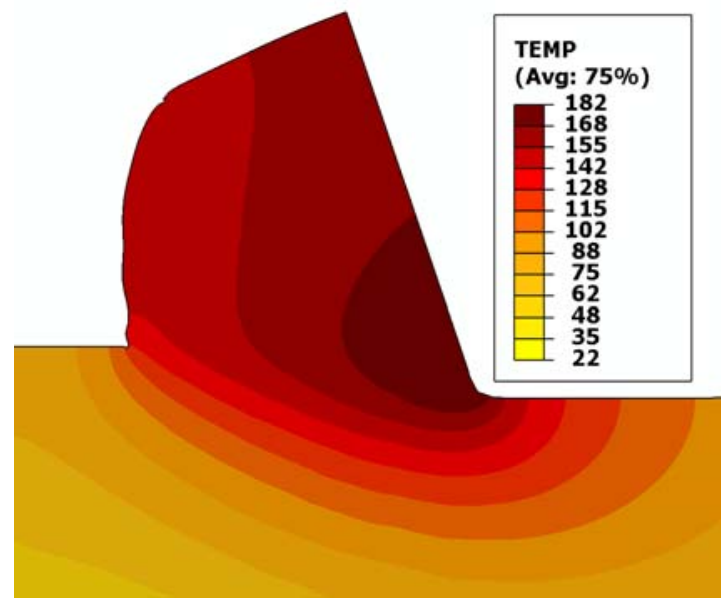

(b) Rake angle $-20^{\circ}$

Fig. 8 Temperature $\left({ }^{\circ} \mathrm{C}\right)$ predictions by the CEL model for orthogonal cutting of $\mathrm{CP} \mathrm{Ti}$

Fig. 9 shows the predictions of the grain size distributions for the two tests. It can be seen that grain size was greatly reduced to a minimum of about $100 \mathrm{~nm}$ not only in the chip but also near the machined surface for both cases. The histograms of predicted grain sizes in the chips are shown in Fig. 10, which clearly shows a further reduction of grain size by about $20 \mathrm{~nm}$ when the rake angle is changed from $20^{\circ}$ to $20^{\circ}$. Table 8 summarizes the grain size predictions and the measurements in the chip and on the machined surface. The predicted average grain size in the chip was $146.3 \pm 13.6$ and $128.7 \pm 21.2 \mathrm{~nm}$ for the tool rake angle of $20^{\circ}$ and $-20^{\circ}$, respectively. The predicted minimum grain size in the chip was 110 and $93 \mathrm{~nm}$ for the tool rake angle of $20^{\circ}$ and $-20^{\circ}$, respectively, while the predicted minimum grain size near the machined surface was 99 and $103 \mathrm{~nm}$ for the tool rake angle of $20^{\circ}$ and $-20^{\circ}$, respectively. The predictions matched well with the measured minimum grain size of about $100 \mathrm{~nm}$ in the chip and near the machined surface.

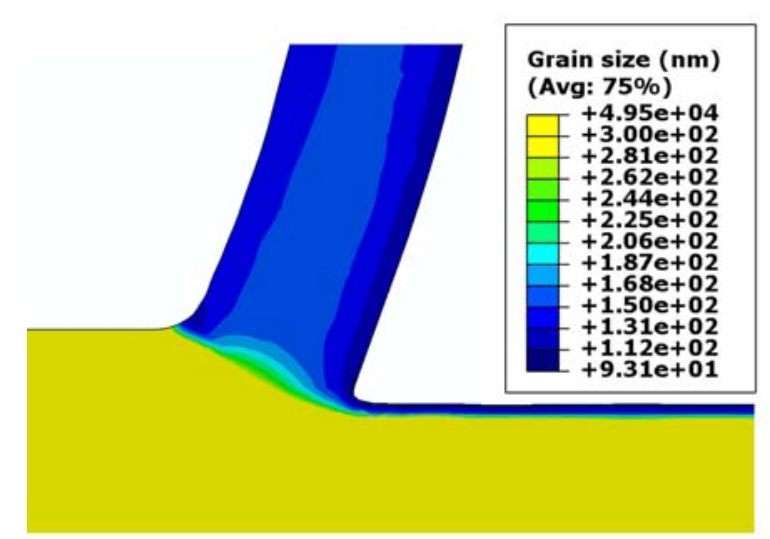

(a) Rake angle $20^{\circ}$

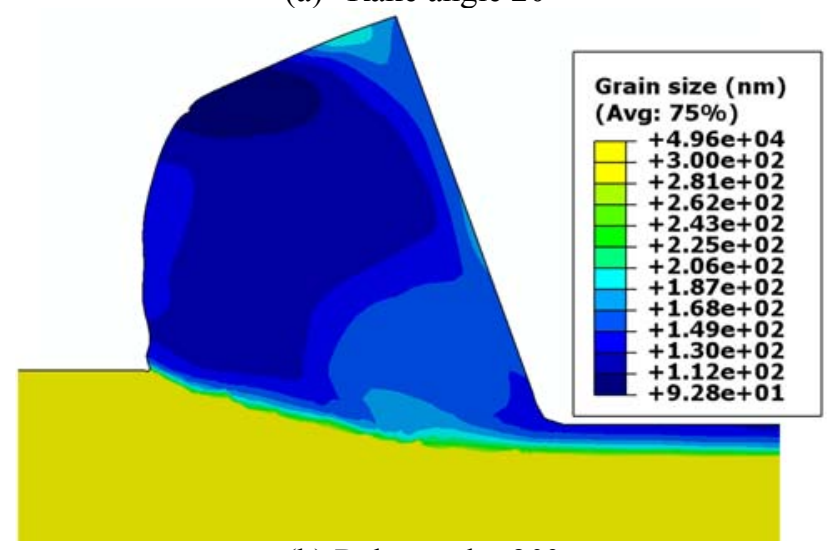

(b) Rake angle $-20^{\circ}$

Fig. 9 Predictions of the grain size $d$ (nm) distribution for orthogonal cutting of $\mathrm{CP} \mathrm{Ti}$ 


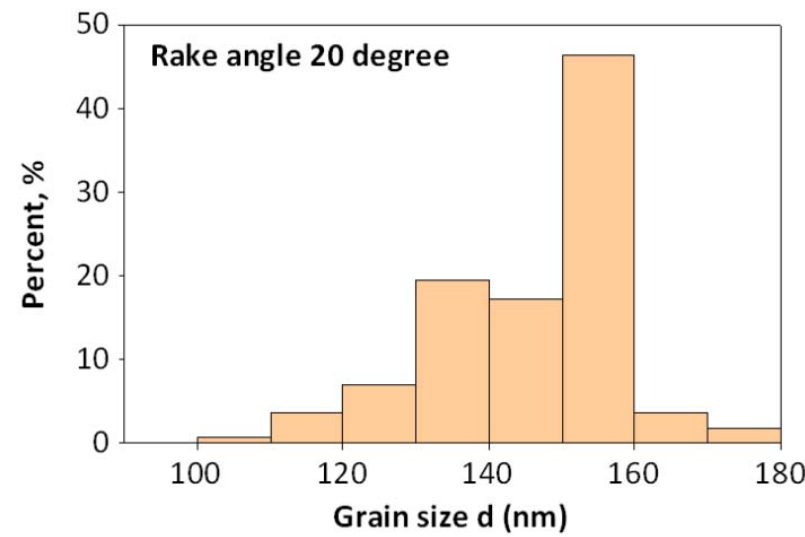

(a) Rake angle $20^{\circ}$

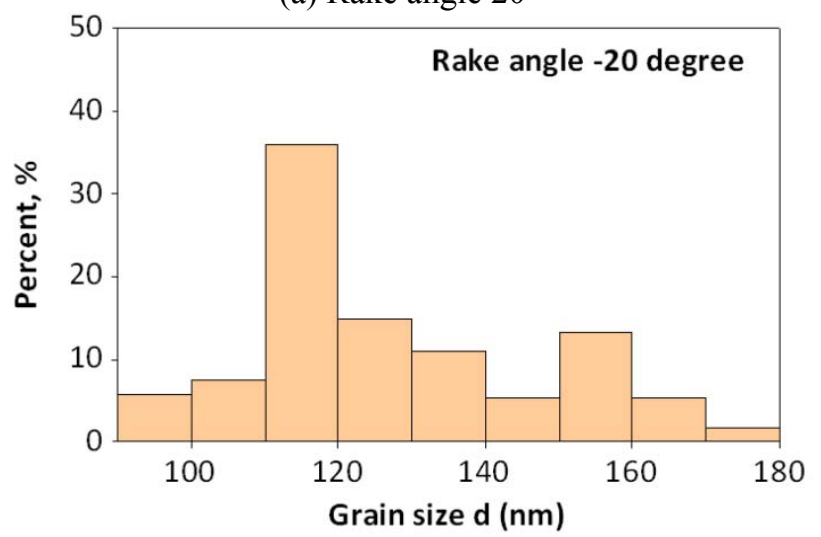

(b) Rake angle $-20^{\circ}$

Fig. 10 Predicted grain size histogram in the chip

\subsection{Discussions}

It is noted that by using the $-20^{\circ}$ rake angle tool, the induced average shear strain in the chip was more than doubled from the case of $20^{\circ}$ rake angle tool. However, the average temperature in the chip also increased by about 80 $100{ }^{\circ} \mathrm{C}$ when using the $-20^{\circ}$ rake angle tool, which adversely affected the grain refinement due to the increase of dislocations annihilations at a higher temperature. The sum of the effects of the strain and temperature increases contributed to the shift of $20 \mathrm{~nm}$ in average grain size from the $20^{\circ}$ to $-20^{\circ}$ rake angle tool. This further tells that the grain refinement mechanism is affected by a combination of process parameters as well as work material properties and is not determined by the induced strain alone. Using a more negative rake angle tool might not further reduce the grain size.

Fig. 11 shows the predicted total dislocation density histograms in the primary shear zone and in the steady-state chip. Dislocations greatly increase as the material enters the primary shear zone from the bulk material zone and further get accumulated as the material becomes chip. Fig. 12 shows the predicted total dislocation density distribution and schematically illustrates the microstructural evolution from the bulk material zone to the primary shear zone and to chip during machining. It shows the initial dislocation distribution and the thermo-mechanical history of the material has little effect on the deformed microstructures developed in the primary shear zone, which has also been observed by $\mathrm{Ni}$ and Alpas [1], Baik et al. [17] and Mishra [27]. As the material enters the primary shear zone, the dislocation cell structure is greatly elongated and new dislocations dramatically increase on the cell walls and some are blocked by the subgrain boundaries. As the deformation continues into the steadystate chip zone, elongated subgrains break up and are reoriented into ultrafine grains.

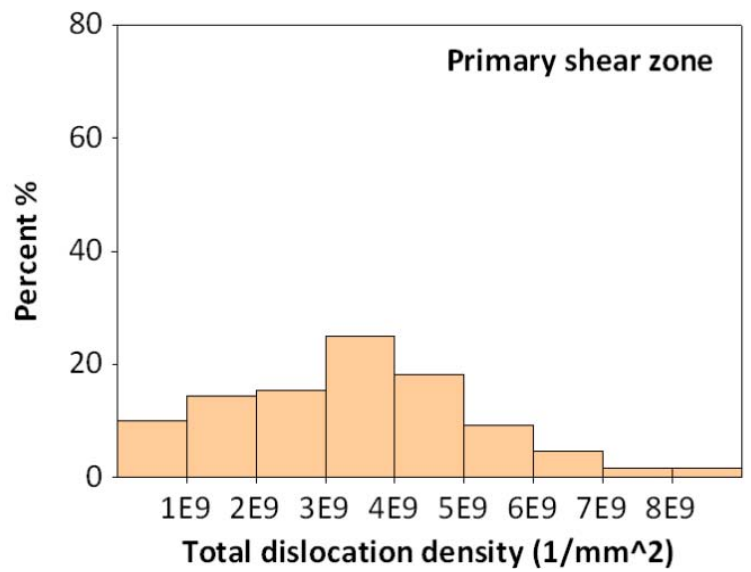

(a) In the primary shear zone

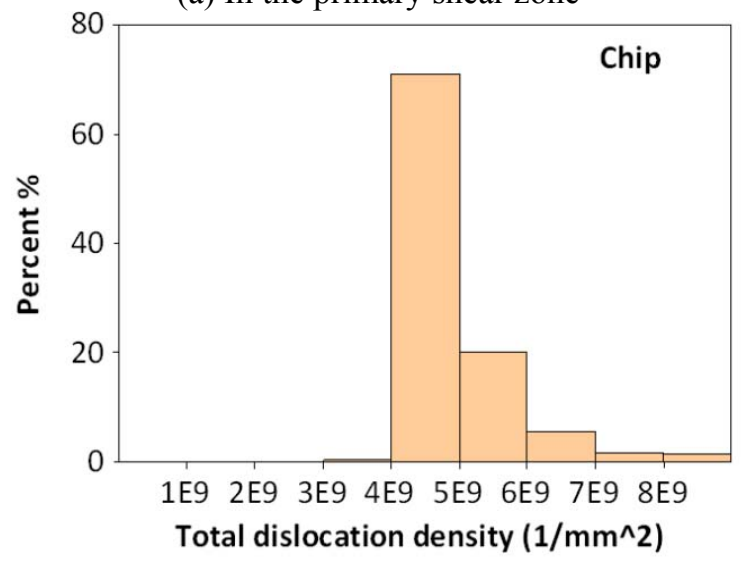

(b) In the steady-state chip

Fig. 11 Predicted total dislocation density $\left(1 / \mathrm{mm}^{2}\right)$ histograms

\section{CONCLUSIONS}

In this paper, a finite element based numerical framework was developed to simulate chip formation and grain refinement by machining. A dislocation density-based material model developed for ECAP was adapted to model the material microstructure evolution in machining. A novel CEL finite element model by incorporating the dislocation material subroutine was developed to model steady-state cutting with grain refinement. The validity of this approach was assessed through a direct comparison with literature data on the orthogonal cutting tests of a commercially pure titanium material. The dislocation density-based material model was calibrated to reproduce the observed material constitutive 
behaviors of $\mathrm{CP} \mathrm{Ti}$ under various strains, strain rates and temperatures similar to those occurring in the cutting process. The results demonstrated that the essential characteristics of the mechanical behavior were captured by the newly developed model very well. In particular, the deformation behaviors under a wide temperature range of ambient to 750 ${ }^{\circ} \mathrm{C}$ were correctly modeled with the calibration of the temperature-dependent dislocation model control parameters.

The CEL model predictions of steady-state chip morphology, strain rate distribution and strains in the chip and near the machined surface all matched well with the actual measurements. Largest strains were predicted in the secondary shear zone along the tool-chip contact and on the machined surface. A very steep strain gradient was predicted for a shallow layer below the machined surface, which confirmed the experimental observation of grain refinement near the machine surface. The CEL model predicted grain size refinement to a minimum of about $100 \mathrm{~nm}$ not only in the chip but also near the machined surface for cutting of CP Ti. The predicted minimum grain size in the chip was 110 and 93 $\mathrm{nm}$ for the tool rake angle of $20^{\circ}$ and $-20^{\circ}$, respectively, while the predicted minimum grain size near the machined surface was 99 and $103 \mathrm{~nm}$ for the tool rake angle of $20^{\circ}$ and $-20^{\circ}$, respectively. Therefore, the CEL model coupled with a dislocation model developed in this study has been shown to be a powerful tool to model grain refinement by cutting and can be used to better design process parameters to achieve optimum mechanical properties of the refined microstructure.

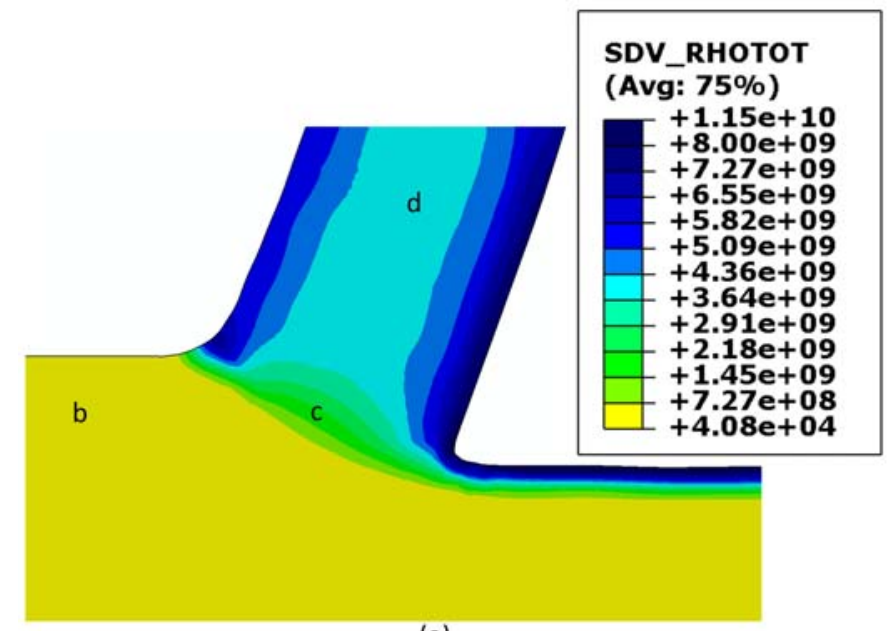

(a)

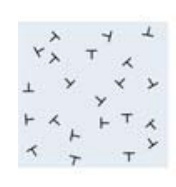

(b)

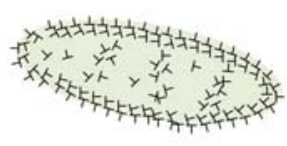

(c)

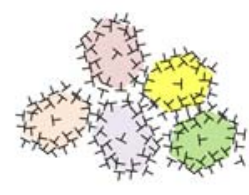

(d)
Fig. 12. Schematic illustration of microstructural evolution during machining. (a) Predicted total dislocation density $\left(1 / \mathrm{mm}^{2}\right)$ distribution (b) homogeneous, loosely distribution of dislocations in the bulk material (c) elongated dislocation cell in the chip primary shear zone, with dense dislocations on the cell walls and blocked dislocations by subgrain boundaries (d) well developed sub-micron grains in the chip, by break up and reorientation of subgrains.

\section{Acknowledgment}

The authors wish to gratefully acknowledge the financial support provided for this study by the National Science Foundation (Grant No: 0538786-IIP, 0917936-IIP), State of Indiana through the 21 st Century R\&T Fund, and Industrial Consortium members of the Center for Laser-based Manufacturing.

\section{References:}

[1] Ni, H., and Alpas, A. T., 2003, "Sub-micrometer structures generated during dry machining of copper," Materials Science and Engineering: A, 361(1-2), pp. 338349.

[2] Elmadagli, M., and Alpas, A. T., 2003, "Metallographic analysis of the deformation microstructure of copper subjected to orthogonal cutting," Materials Science and Engineering: A, 355(1-2), pp. 249-259.

[3] Swaminathan, S., Shankar, M. R., Lee, S., Hwang, J., King, A. H., Kezar, R. F., Rao, B. C., Brown, T. L., Chandrasekar, S., Compton, W. D., and Trumble, K. P., 2005, "Large strain deformation and ultra-fine grained materials by machining," Materials Science and Engineering: A, 410-411, pp. 358-363.

[4] Zhang, H., and Alpas, A. T., 2002, "Quantitative evaluation of plastic strain gradients generated during orthogonal cutting of an aluminum alloy," Materials Science and Engineering: A, 332(1-2), pp. 249-254.

[5] Shankar, M. R., Rao, B. C., Lee, S., Chandrasekar, S., King, A. H., and Compton, W. D., 2006, "Severe plastic deformation (SPD) of titanium at near-ambient temperature," Acta Materialia, 54(14), pp. 3691-3700.

[6] Shankar, M. R., Verma, R., Rao, B. C., Chandrasekar, S., Compton, W. D., King, A. H., and Trumble, K. P., 2007, "Severe plastic deformation of difficult-to-deform materials at near-ambient temperature," Metallurgical and Materials Transactions A: Physical Metallurgy and Materials Science, 38A(9), pp. 1899-1905.

[7] Stolyarov, V. V., Zhu, Y. T., Alexandrov, I. V., Lowe, T. C., and Valiev, R. Z., 2003, "Grain refinement and properties of pure Ti processed by warm ECAP and cold rolling," Materials Science and Engineering: A, 343(1-2), pp. 43-50.

[8] Petryk, H., and Stupkiewicz, S., 2007, "A quantitative model of grain refinement and strain hardening during severe plastic deformation," Materials Science and Engineering: A, 444(1-2), pp. 214-219.

[9] Petryk, H., Stupkiewicz, S., and Kuziak, R., 2008, "Grain refinement and strain hardening in IF steel during multi- 
axis compression: Experiment and modelling," Journal of Materials Processing Technology, 204(1-3), pp. 255-263.

[10] Beygelzimer, Y., 2005, "Grain refinement versus voids accumulation during severe plastic deformations of polycrystals: mathematical simulation," Mechanics of Materials, 37(7), pp. 753-767.

[11] Mohamed, F. A., 2003, "A dislocation model for the minimum grain size obtainable by milling," Acta Materialia, 51(14), pp. 4107-4119.

[12] Mohamed, F. A., and Xun, Y., 2003, "On the minimum grain size produced by milling $\mathrm{Zn}-22 \% \mathrm{Al}$," Materials Science and Engineering: A, 358(1-2), pp. 178-185.

[13] Mohammed, F. A., and Xun, Y., 2003, "Correlations between the minimum grain size produced by milling and material parameters," Materials Science and Engineering: A, 354(1-2), pp. 133-139.

[14] Mohamed, F. A., 2010, "Correlation between the behavior of nanocrystalline HCP metals and the dislocation model for the minimum grain size obtainable by milling," Materials Science and Engineering: A, 527(9), pp. $2157-$ 2162.

[15] Starink, M. J., Qiao, X. G., Zhang, J., and Gao, N., 2009, "Predicting grain refinement by cold severe plastic deformation in alloys using volume averaged dislocation generation," Acta Materialia, 57(19), pp. 5796-5811.

[16] Estrin, Y., Tóth, L. S., Molinari, A., and Bréchet, Y., 1998, "A dislocation-based model for all hardening stages in large strain deformation," Acta Materialia, 46(15), pp. 5509-5522.

[17] Toth, L. S., Molinari, A., and Estrin, Y., 2002, "Strain hardening at large strains as predicted by dislocation based polycrystal plasticity model," Trans. of the ASME, Journal of Engineering Materials and Technology, 124, pp. 71-77.

[18]Baik, S. C., Hellmig, R. J., Estrin, Y., and Kim, H. S., 2003, "Modeling of deformation behavior of copper under equal channel angular pressing," Zeitschrift fur Metallkunde, 94, pp. 754-760.

[19]Baik, S. C., Estrin, Y., Kim, H. S., and Hellmig, R. J., 2003, "Dislocation density-based modeling of deformation behavior of aluminium under equal channel angular pressing," Materials Science and Engineering: A, 351(1-2), pp. 86-97.
[20]Baik, S. C., Estrin, Y., Kim, H. S., Jeong, H.-T., and Hellmig, R. J., 2002, "Calculation of deformation behavior and texture evolution during equal channel angular pressing of IF steel using dislocation based modeling of strain hardening," Materials Science Forum, 408-412, pp. 697-702.

[21] Kim, H. S., and Estrin, Y., 2005, "Microstructural modelling of equal channel angular pressing for producing ultrafine grained materials," Materials Science and Engineering: A, 410-411, pp. 285-289.

[22] Lemiale, V., Estrin, Y., Kim, H. S., and O'Donnell, R., 2010, "Grain refinement under high strain rate impact: A numerical approach," Computational Materials Science, 48(1), pp. 124-132.

[23] Miguélez, M. H., Munoz-Sanchez, A., Cantero, J. L. and Loya, J. A., 2009, “An efficient implementation of boundary conditions in an ALE model for orthogonal cutting," Journal of Theoretical and Applied Mechanics, 47, pp. 599-616.

[24] Miguélez, M. H., Zaera, R., Molinari, A., Cheriguene, R. and Rusinek, A., 2009, "Residual stresses in orthogonal cutting of metals: The effect of thermomechanical coupling parameters and of friction," Journal of Thermal Stresses, 32, pp. 269-289.

[25] Lampman, S., 1990, "Wrought titanium and titanium alloys," Properties and selection: nonferrous alloys and special-purpose materials, ASM Handbook, ASM International, Vol. 2, pp. 592-633.

[26] Sheikh-Ahmad, J. Y. and Bailey, J. A., 1995, “A constitutive model for commercially pure titanium," Transactions of the ASME, Journal of Engineering Materials and Technology, 117, pp. 139-144.

[27] Mishra, A., Kad, B. K., Gregori, F., and Meyers, M. A., 2007, "Microstructural evolution in copper subjected to severe plastic deformation: Experiments and analysis," Acta Materialia, 55(1), pp. 13-28 